\title{
PENERAPAN RAPID APPLICATION DEVELOPMENT PADA SISTEM PENJUALAN SEPEDA ONLINE
}

\author{
Sandy Kosasi \\ Program Studi Sistem Informasi \\ STMIK Pontianak \\ Email: sandykosasi@yahoo.co.id \\ I Dewa Ayu Eka Yuliani \\ Program Studi Sistem Informasi \\ STMIK Pontianak \\ Email: dewaayu.ekayuliani@gmail.com
}

\begin{abstract}
ABSTRAK
Tujuan penelitian menerapkan metode RAD (Rapid Application Development) untuk menghasilkan sistem penjualan sepeda online melalui integrasi basis data dan membangun hubungan dengan pelanggan secara lebih personal. Sasarannya lebih kearah memperluas jangkauan pemasaran dan meningkatkan penjualan melalui media yang lebih fleksibel dan lebih ekonomis. Pemodelan sistemnya menggunakan UML (Unified Modeling Language). Penelitian berbentuk studi kasus dengan metode penelitian research and development (R\&D). Perancangan sistem perangkat lunak meliputi bagian front-end dan sistem manajemen konten yang secara spesifik meniadakan perantara, mengurangi biaya operasional penjualan, menpermudah pengiriman, dan penerimaan pembayaran secara online. Hasil pengujian memperlihatkan proses digitisasi penjualan memiliki verifikasi yang akurat mengenai sistem navigasi, pendataan isi keranjang belanja, mudah menelusuri pemrosesan data pemesanan, dan konfirmasi penerimaan pembayaran.
\end{abstract}

Kata kunci: sistem penjualan online, metode $\mathrm{RAD}$, unified modeling language.

\begin{abstract}
The purpose of the research applying RAD (Rapid Application Development) method is to produce an online system of bicycle selling through the integration of database and build relationships with customers in a more personalized way. The aim extends more on the marketing reach and increases sales through the more flexible and more economical media. The modeling system uses UML (Unified Modeling Language). This research is in form of case study and uses research \& development $(R \& D)$ method. The design of the software system includes the front-end part and content management system specifically excluding intermediaries, reducing operational costs of sales, and easing the shipping and online receiving payment. The test results show that the sales digitization has accurate verification of navigation system, records of shopping cart contents, easy investigation on the processing of ordering data, and confirmation of receipt of payment.
\end{abstract}

Keywords: system of online selling,RAD method, unified modeling language.

\section{PENDAHULUAN}

Untuk menghasilkan sebuah sistem perangkat lunak agar memiliki kinerja yang baik tentunya tidak terlepas dari cara memilih dan menerapkan metode analisis dan perancangannya. Pemilihan metode yang tepat memberikan banyak manfaat dan kemudahan dalam menghasilkan sebuah sistem. Sebuah sistem tidak hanya fokus kepada model dan fitur-fitur dari sebuah perangkat lunak serta bahasa pemrograman dan penggunaan basis datanya. Secara signifikan menerapkan metode secara tepat akan memberikan hasil yang nyata dalam penggunaanya [1]. Untuk sistem yang memiliki tingkat kedinamisan yang tinggi, ketersediaan waktu dan anggran biaya pengembangan yang terbatas, untuk kebutuhan informasi terkini secara cepat, dan perlunya kedekatan interaksi hubungan yang personal dengan karakteristik penggunanya lebih tepat menerapkan metode RAD (Rapid Application Development) [2]. Semua fitur ini sesuai dengan kebutuhan untuk manghasilkan sebuah sistem penjualan sepeda online bagi bisnis UD. Polygon. Merujuk skala usaha yang masih berupa bisnis keluarga dengan segmen pasar masyarakat menengah, jelas memiliki keterbatasan anggaran biaya untuk pengembangannya, namun disisi lain membutuhkan waktu penyelesaian secara cepat. 
Penelitian yang menerapkan metode RAD diantaranya pengembangan aplikasi bahasa sunda dapat berfungsi dengan baik, berdasarkan hasil pengujian responden menyatakan setuju dengan urutan atau tahapan dalam pengembangan aplikasi tersebut [3]. Menerapkan metode RAD harus mempertimbangkan aspek waktu dan biaya secara seimbang dan lebih sesuai untuk pengembangan sistem informasi yang unggul dalam hal kecepatan, ketepatan, dan biaya lebih rendah. Melibatkan pengguna dalam pengembangannya sehingga dapat meningkatkan kepuasan dalam penggunaan sistemnya [4]. Proses pembangunan web e-commerce untuk memperkenalkan dan menjual produk unggulannya kepada masyarakat luas dengan menggunakan RAD hanya membutuhkan waktu sekitar 60 hari. Kebutuhan yang mendesak akan pembangunan web e-commerce, menjadi alasan terpilihnya metode pengembangan RAD, agar keinginan masyarakat dapat segera terpenuhi [5]. Sistem penjualan online dapat mempermudah proses transaksi, sarana promosi penjualan secara online. Penelitian ini menggunakan perangkat lunak bahasa pemrograman PHP, Netoped++, Dreamweaver [6]. Penerapan metode RAD sebagai bagian dari ADMMC (Agile based development methodology for mobile commerce applications) lebih bersifat aplikatif, praktis dan mudah menyesuaikan untuk kebutuhan sistem perangkat bergerak dibandingkan dengan metode waterfall [7].

Dalam penelitian ini menerapkan metode RAD dalam menghasilkan sistem penjualan sepeda online bagi UD. Polygon. Selama ini sistem penjualannya masih mengandalkan media interaksi dengan konsumen secara langsung dan masih berpusat kepada lokasi tertentu. Hal ini tentunya menyulitkan pihak manajemen untuk memperluas pangsa pasarnya. Di sisi lain, jumlah pesaing yang semakin bertambah menyebabkan perusahaan semakin sulit memelihara performansi dan kinerja dengan tingkat profitabilitasnya. Konsumen seringkali sulit mengakses berbagai informasi tentang produk, informasi harga terbaru, media promosi terbatas dan cenderung tidak fleksibel, hambatan personalisasi, dan biaya operasional yang semakin meningkat. Mobilitas dan liberalisasi pasar yang terbatas membuat pihak manajemen harus melakukan inovasi perluasan pasar sasaran melalui penjualan online. Konsumen dapat melakukan pemesanan dan pembelian dimana saja tanpa batasan tempat dan waktu, serta memiliki daya tanggap akan kekinian informasi sesuai personalisasi kebutuhan konsumen. Tujuan penelitian menerapkan metode RAD untuk menghasilkan sistem penjualan sepeda online melalui integrasi basis data dan membangun hubungan dengan pelanggan secara lebih personal. Sasarannya lebih kearah memperluas jangkauan pemasaran dan meningkatkan penjualan melalui media yang lebih fleksibel dan lebih ekonomis.

\section{METODE PENELITIAN}

Penelitian ini berbentuk studi kasus menggunakan metode penelitian research \& development (R\&D) dan metode analisis dan perancangan aplikasinya menggunakan metode RAD (Rapid Application Development) (Gambar 1) [8]. Untuk pemodelan sistem menggunakan UML (Unified Modeling Language) [8]. Metode RAD sebagai salah satu alternatif dari metode SDLC (System Development Life Cycle) belakangan ini sudah banyak yang menerapkannya untuk mengatasi keterlambatan yang terjadi apabila menggunakan metode konvensional. Metode RAD sesuai untuk menghasilkan sistem perangkat lunak dengan kebutuhan yang mendesak dan waktu yang singkat dalam penyelesaiannya. Metode RAD merupakan pendekatan berorientasi objek untuk menghasilkan sebuah sistem dengan sasaran utama mempersingkat waktu pengerjaan aplikasi dan proses agar sesegera mungkin memberdayakan sistem perangkat lunak tersebut secara tepat dan cepat [9]. Untuk perancangan suatu sistem informasi yang normal seandainya membutuhkan waktu minimal 180 hari, maka dengan menerapkan metode RAD hanya membutuhkan waktu 30-90 hari untuk menyelesaikan sistem perangkat lunak tersebut. Metode ini sangat mementingkan keterlibatan pengguna dalam proses analisis dan perancangannya, dan dengan demikian dapat memenuhi kebutuhan pengguna dengan baik dan secara nyata akan dapat meningkatkan tingkat kepuasan pengguna sistem [10].

Instrumen penelitian dengan teknik wawancara dan observasi, dan pengambilan sampelnya menggunakan teknik purposive sampling. Pemilihan cara pengujian dilakukan dengan menggunakan data yang mudah diperiksa (easy values), data yang sederhana dan mudah dihitung (typical realistic values), data yang ekstrim (extreme values) dan data yang tidak diperbolehkan (illegal values) [11]. Metode analisis perluasan pasar untuk memperoleh sejumlah fitur-fitur penting bagi kebutuhan konsumen dengan menggunakan analisis kesempatan pasar, dan melakukan dengan menggunakan perancangan model bisnis, antarmuka pelanggan, komunikasi pasar dan rancangan implementasi [12]. 


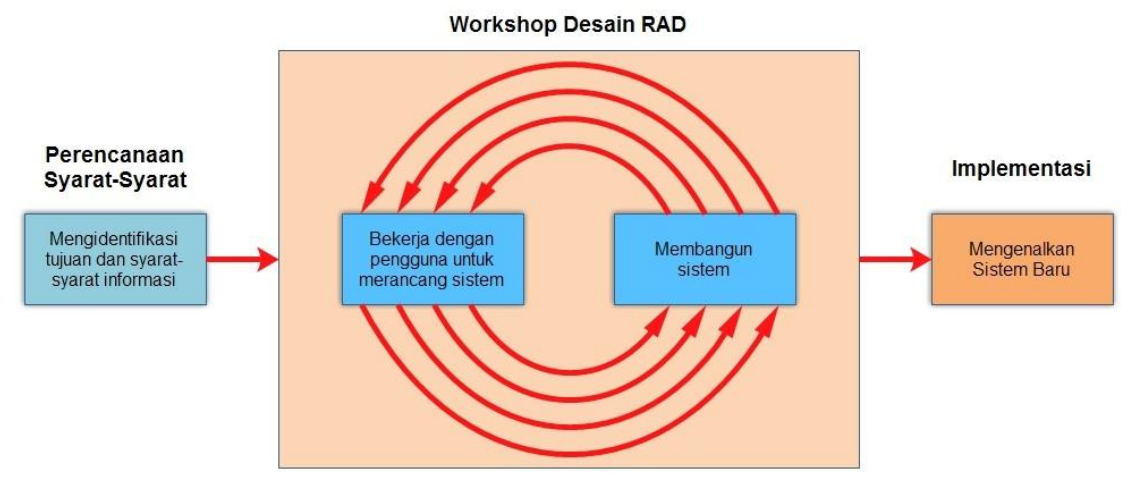

Gambar 1. Metode RAD (Rapid Application Development)

Kebutuhan analisis diawali mengidentifikasi sejumlah pesaing sejenis, yang mana belum banyak memanfaatkan media internet dalam model pemasaran online sehingga merupakan peluang bagus [13]. Keterbatasan faktor teknis seperti kecepatan akses, kemampuan server, dan kemudahan akses. Memberi kemudahan akses informasi yang selama ini masih menjadi persoalan. Media promosi yang dinamis dapat meningkatkan jumlah transaksi dan pelanggan. Belum semuanya memiliki jaringan infrastruktur internet yang stabil dan normal. Sisi produk memiliki faktor kekhasan khusus sehingga membutuhkan media digitisasi penjualan melalui media website. Dalam merancang antarmuka menggunakan pendekatan 7C (Context, Content, Community, Customization, Communication, Connection, Commerce). Untuk komunikasi pasar dapat melalui mesin pencari, iklan online, media cetak, dan majalah. Dalam implementasinya harus memperhatikan keterampilan sumber daya manusia dan sumberdaya teknologi informasi [14-15].

\section{HASIL PENELITIAN DAN PEMBAHASAN}

Metode RAD (Rapid Application Development) menggunakan metode iteratif (berulang) dalam mengembangkan sistem dimana model bekerja sistem dikonstruksikan di awal tahap pengembangan dengan tujuan menetapkan kebutuhan pengguna. Metode RAD menekankan cakupan pemodelan bisnis (bussiness modelling), pemodelan data (data modelling), pemodelan proses (process modelling), pembuatan aplikasi (application generation) dan pengujian (testing). Untuk tahap awal melakukan pemenuhan kebutuhan pengguna. Dalam fase ini semua kebutuhan pengguna yang berkaitan dengan perancangan sistem penjualan sepeda online. Fase ini, pengguna dan penganalisis bertemu untuk mengidentifikasikan tujuan-tujuan aplikasi atau sistem serta untuk mengidentifikasikan syarat-syarat informasi yang ditimbulkan dari tujuan-tujuan tersebut. Orientasi dalam fase ini adalah menyelesaikan masalah-masalah perusahaan. Meskipun teknologi informasi dan sistem bisa mengarahkan sebagian dari sistem yang diajukan, fokusnya akan selalu tetap pada upaya pencapaian tujuan-tujuan perusahaan. Pengembang sistem harus dapat mencari informasi untuk memenuhi kebutuhan aplikasi ini. Sistem informasi penjualan sepeda online berbasis web adalah sebuah sistem informasi yang akan membantu dalam memperlancar proses bisnis penjualan sepeda yang selama ini dilakukan secara konvensional dengan hanya mengandalkan pelanggan mendatangi UD. Polygon. Kehadiran sistem informasi penjualan sepeda online ini akan dapat membantu pihak usaha UD. Polygon dalam menjual sepeda kepada konsumen secara online dengan memanfaatkan teknologi internet. Konsumen yang ingin mencari sepeda dapat bertransaksi secara langsung melalui sistem ini dengan hanya mengakses website penjualan sepeda ini.

Fase perancangan sistem penjualan sepeda online menerapkan strategi back-end dan front-end. Dimana backend merupakan halaman yang di khususkan bagi admin untuk mengelola website tersebut. Sementara halaman front-end disediakan untuk pengguna akhir (end-user) dalam hal ini pengunjung website, baik yang hanya sekedar ingin melihat informasi maupun bagi mereka yang ingin mencari dan membeli sepeda. Penganalisis dan pemrogram dapat bekerja membangun dan menunjukkan representasi visual desain dan pola kerja kepada pengguna. Waktu perancangan bergantung dari ukuran aplikasi yang akan dikembangkan. Selama fase perancangan, pengguna merespon prototipe yang ada dan penganalisis memperbaiki modul-modul yang dirancang berdasarkan respon pengguna. Untuk mempermudah dalam pemahaman model arsitektur pengembangan sistem, perlu memahami model dari arsitektur sistem Penjualan sepeda online. Seperti dalam arsitektur tradisional, fokusnya adalah benar pada pengguna dan kebutuhan pengguna. Hal ini memerlukan perhatian khusus pada konten web, rencana bisnis, kegunaan, perancangan interaksi, informasi dan perancangan arsitektur website. Model arsitektur ini mendeskripsikan perancangan dari perangkat lunak disisi web server dan client. Web server menggunakan apache, script PHP dan menggunakan basis data $M y S Q L$. 
Dalam fase perancangan mengindentifikasikan semua struktur sistem, prinsip komponen (sub-sistem/modul), hubungannya dan model pendistribusi informasinya. Berdasarkan pemahaman dari sistem yang berjalan, dalam hal ini menggunakan website sebagai media untuk melakukan penjualan secara online. Perancangan sistem ini dapat memberikan kemudahan bagi pengguna karena memiliki interface yang sederhana dan mudah memahaminya dan dapat menangani masalah pengelolaan data profil, sepeda yang dijual, deskripsi sepeda secara detil dan pemesanan secara online dimana data yang tersimpan dalam bentuk file yang terpusat dalam bentuk server dan kemudian diproses oleh komputer. Perancangan arsitektur mempresentasi kerangka kerja dari sistem perangkat lunak yang dibangun. Deskripsi arsitektur mengadopsi spesifikasi sistem, model analisis, dan interaksi subsistem yang telah didefenisikan pada tahap analisis (Gambar 2).

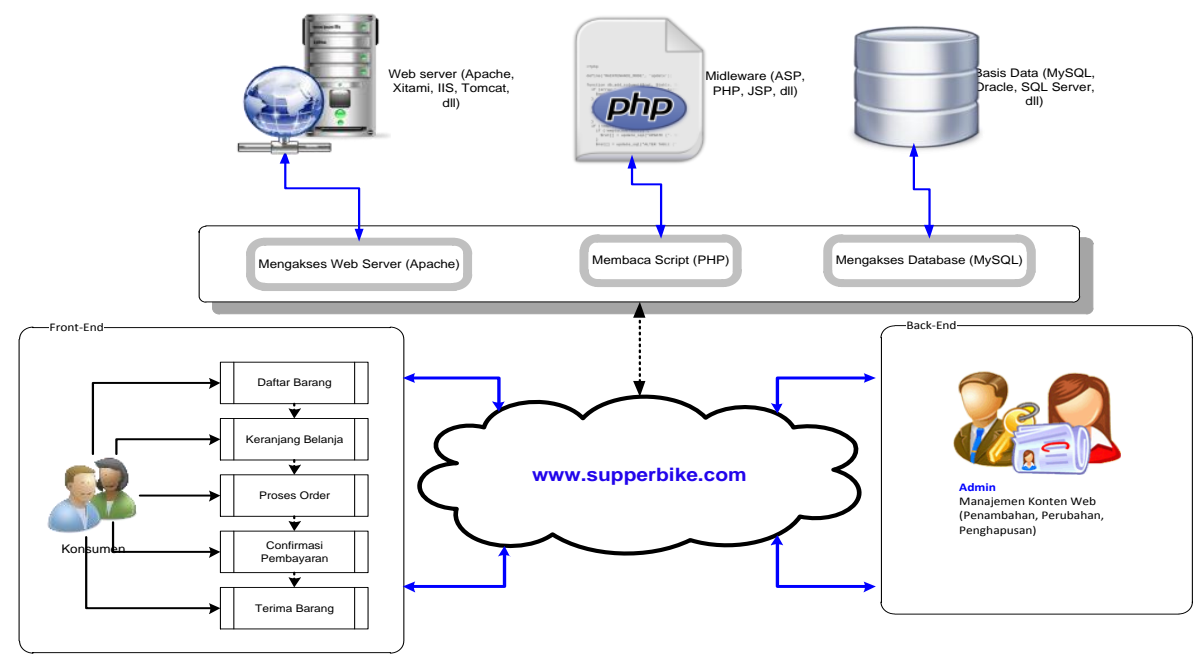

Gambar 2. Metode RAD (Rapid Application Development)

Untuk perancangan model arsitektur sistem jaringan dimaksudkan untuk memberikan deskripsi dari kebutuhan hardware jaringan dan model web hostimg dari arsitektur teknologi jaringan yang mendukung dalam penerapan sistem penjualan sepeda online (Gambar 3).

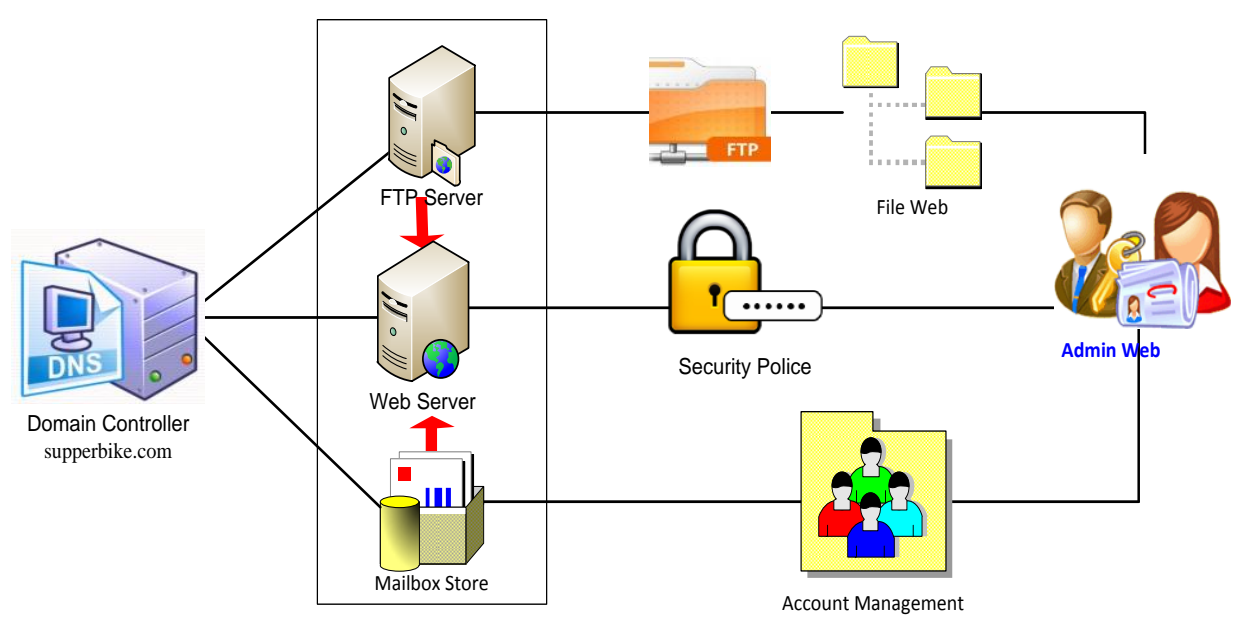

Gambar 3. Arsitektur Web Hosting Sistem Penjualan Sepeda Online

Untuk pemodelan sistem penjualan sepeda online ini diawali dengan menampilkan diagram use case. Diagram ini untuk menjelaskan manfaat penggunaan sistem menurut sudut pandangan orang yang berada di luar sistem atau actor. Diagram ini menunjukkan fungsionalitas suatu sistem atau kelas dari cara kerja sistem berinteraksi dengan dunia luar. Diagram use case pengelolaan konten website sistem penjualan sepeda online terdiri dari admin, pelanggan dan guest. Actor admin bertugas untuk memanajemen isi dari website secara keseluruhan. Actor pelanggan mengelola isi dari profil sendiri, melihat promosi khusus, memesan sepeda dan melakukan konfirmasi pembayaran. Sedangkan actor guest adalah pengunjung website yang ingin mendapatkan informasi mengenai sepeda (Gambar 4). 


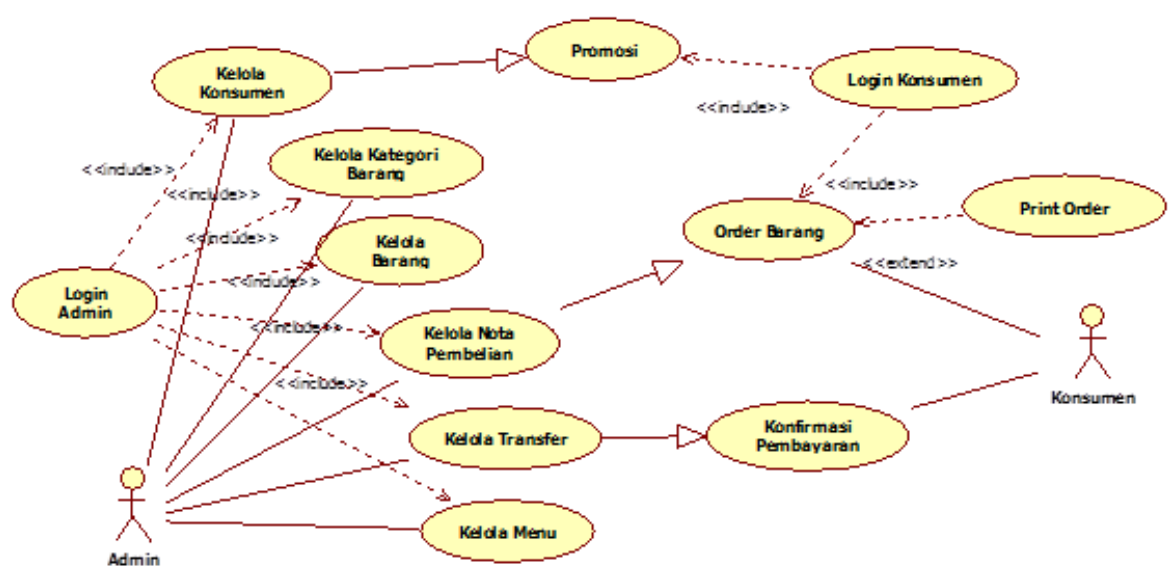

Gambar 4. Diagram Use Case Sistem Penjualan Sepeda Online

Selanjutnya untuk menggambarkan berbagai alur aktivitas dalam sistem yang sedang dirancang, bagaimana masing-masing alur berawal, keputusan yang mungkin terjadi, dan cara kerja sistem melalui diagram activity. Pengelolaan data sepeda oleh admin dimulai dari pemilihan form data sepeda. Form data sepeda ditampilkan lengkap dengan data yang diambil dari basis data. Pada form data sepeda, admin dapat menghapus sepeda atau menambah data sepeda. Apabila admin menambah data sepeda maka form data sepeda akan ditampilkan. Admin mengisikan data sepeda sesuai dengan item yang terdapat pada form tambah data sepeda. Setelah data sepeda diisi dengan lengkap, maka admin mengklik tombol simpan dan proses pengelolaan data sepeda selesai (Gambar 5).

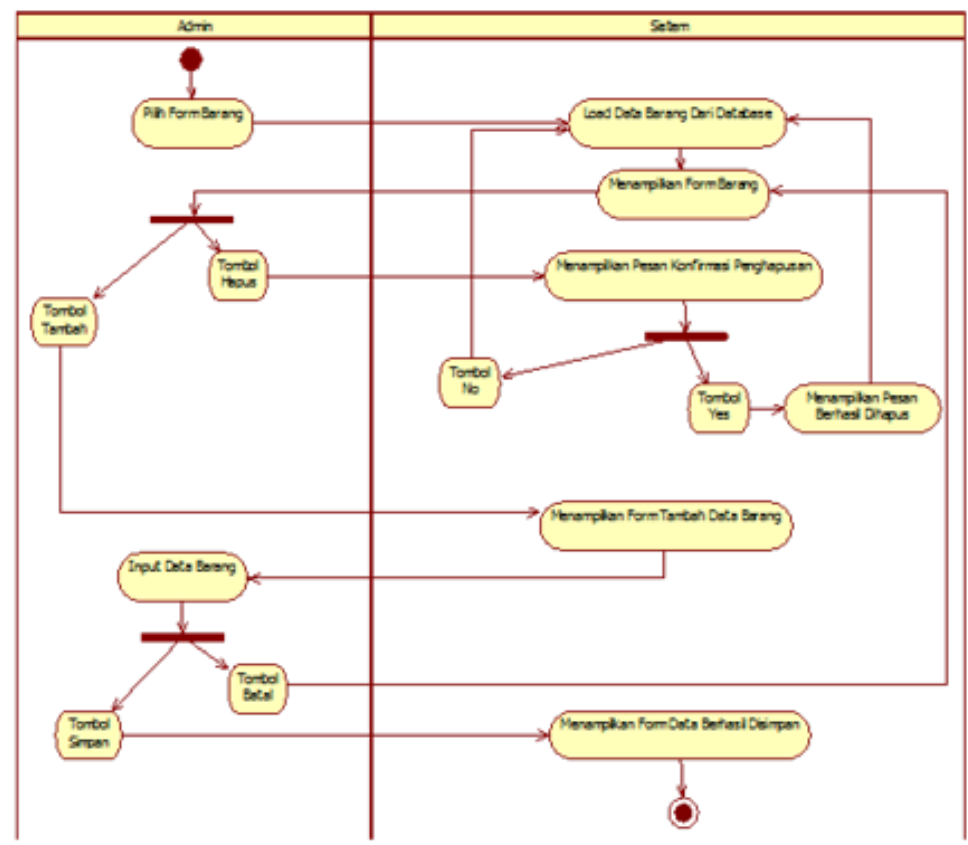

Gambar 5. Diagram Activity Mengelola Data Sepeda

Untuk pemesanan sepeda dimulai dari konsumen dengan memilih sepeda. Sistem menampilkan data sepeda secara detil. Pada tampilan detil data sepeda, konsumen bisa melakukan proses order dengan cara mengklik tombol order. Setelah tombol order diklik maka data sepeda yang diorder akan masuk ke dalam basis data. Setelah data masuk, maka konsumen dapat mencetak bukti order dan sistem akan mencetak (Gambar 6). 


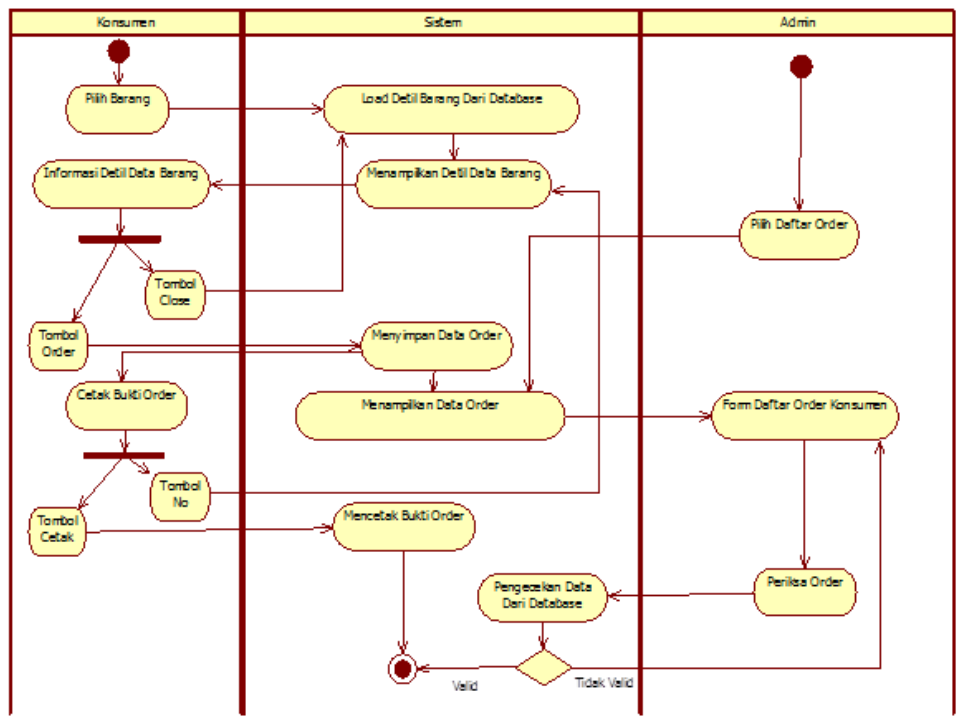

Gambar 6. Diagram Activity Mengelola Pemesanan Sepeda

Untuk mendeskripsikan interaksi antarobjek di dalam dan di sekitar sistem (termasuk pengguna, display, dan sebagainya) berupa message yang digambarkan terhadap waktu menggunakan diagram sequence. Diagram sequence memperlihatkan saat konsumen memilih form konfirmasi pembayaran untuk memberitahukan bahwa sepeda yang sudah dipesan telah dilakukan pembayaran sesuai dengan nilai yang ada pada bukti pemesanan. Sistem menampilkan form konfirmasi pembayaran dan konsumen mengisikan data sesuai dengan item yang terdapat pada form konfirmasi pembayaran. Setelah selesai diinputkan maka konsumen dapat mengklik tombol simpan data sistem menampilkan pesan bahwa data telah berhasil disimpan (Gambar 7).

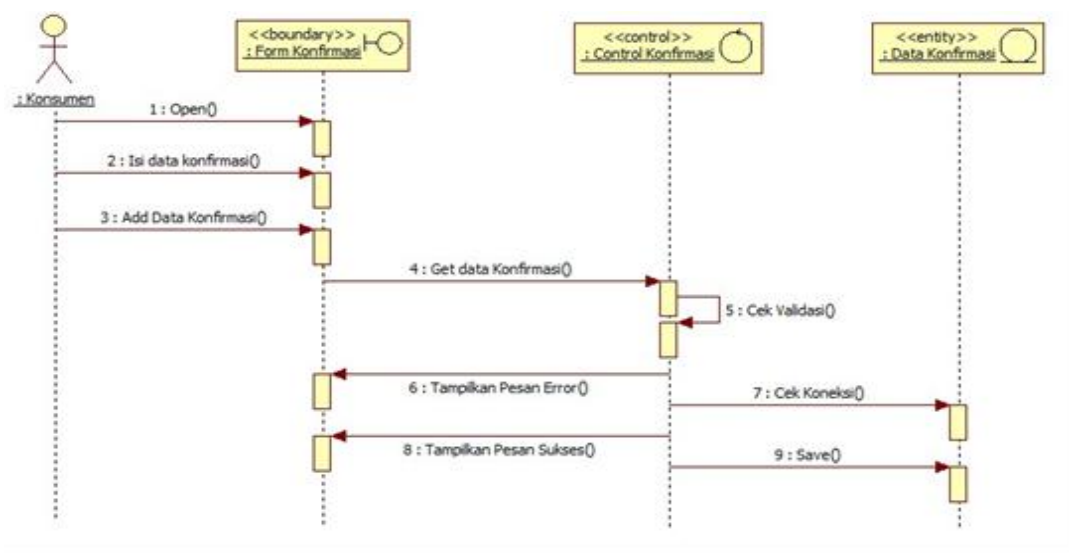

Gambar 7. Diagram Sequence Konfirmasi Pembayaran

Pada fase berikutnya, semua pesan (message) akan dipetakan menjadi operasi/metode dari class. Diagram class untuk menampilkan beberapa penggunaan dari kelas serta paket-paket yang ada dalam sistem perangkat lunak. Adapun kelas-kelas tersebut adalah nota, pembayaran, promosi, barang, detail kategori, kategori, konsumen dan keranjang. Diagram class juga memberikan gambaran (diagram statis) tentang sistem perangkat lunak dan relas-relasi yang ada didalamnya (Gambar 8). 


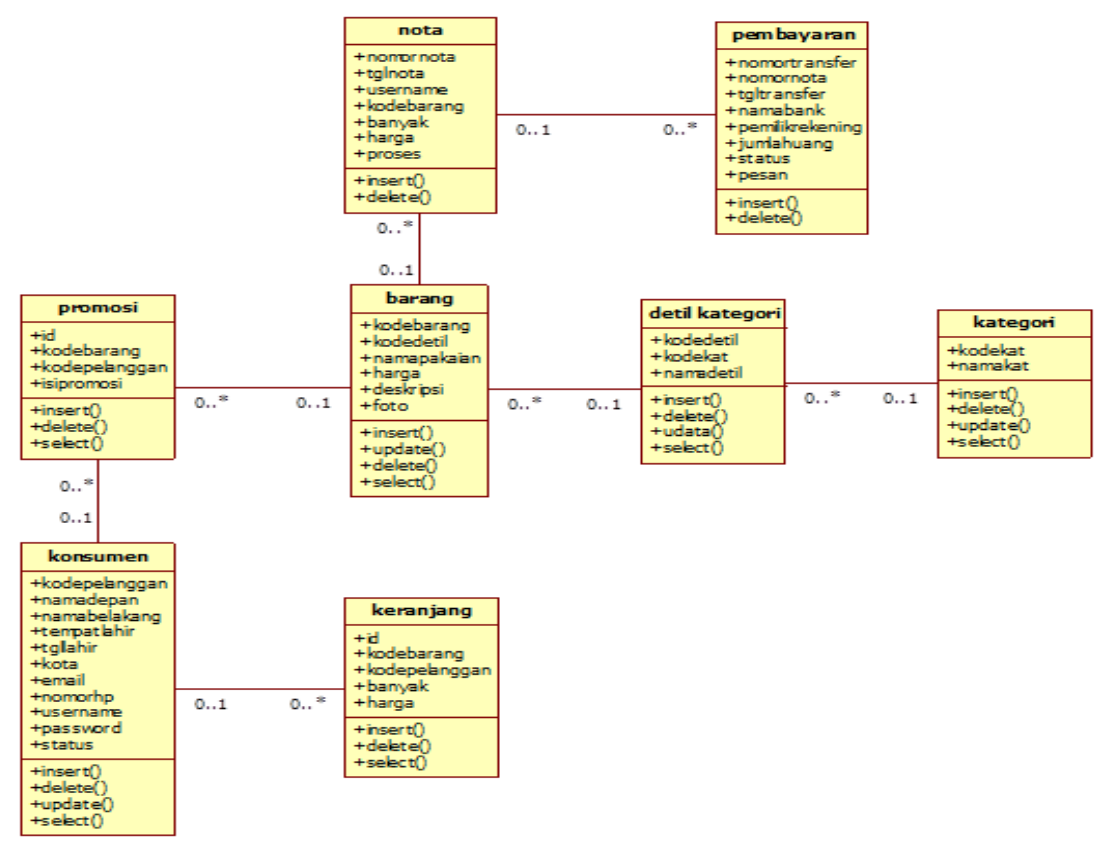

Gambar 8. Diagram Class Sistem Penjualan Sepeda Online

Selanjutnya untuk fase konstruksi adalah untuk menunjukkan platform, hardware dan software yang digunakan serta batasan dalam implementasi, serta menguji performansi prototipe perangkat lunak yang telah dibangun agar dapat diketahui apakah prototipe tersebut telah sesuai dengan spesifikasi analisis dan perancangan yang telah diidentifikasi sebelumnya. Dalam pengimplementasian sistem yang dibuat menggunakan bahasa pemograman $P H P$ dan basis data $M y S q l$. Tools yang digunakan dalam merancangan tampilan input maupun output menggunakan Adobe Dreamweaver CS6 dan EditPlus 2 (Gambar 9).

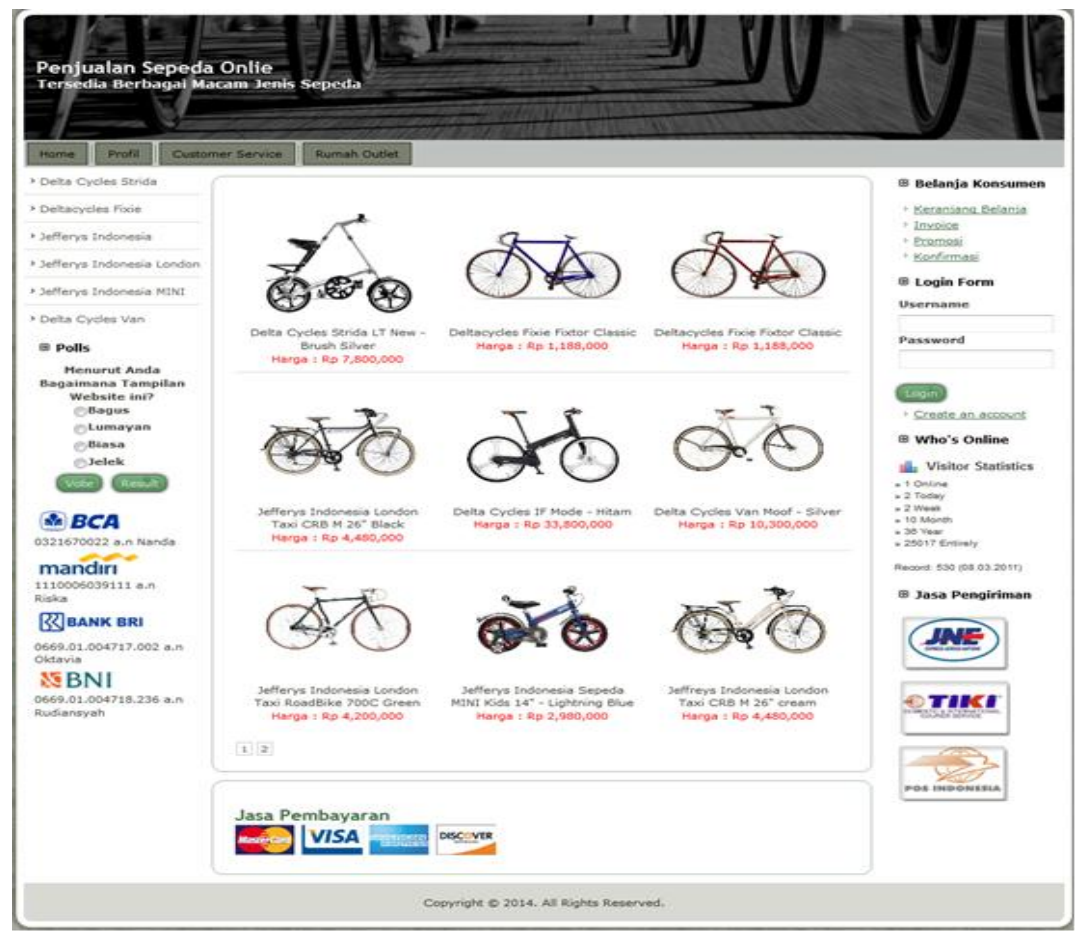

Gambar 9. Hasil Perancangan Menu Utama

Rancangan form detil sepeda dapat dipergunakan oleh konsumen untuk melihat informasi sepeda secara detil. Pada form ini juga konsumen dapat melakukan pembelian terhadap sepeda. Untuk melakukan pembayaran terhadap sepeda yang telah dipesan, maka konsumen harus mengisikan data pada form konfirmasi pembayaran. Namun sebelum mengisikan data, hal terpenting yang harus diketahui oleh konsumen adalah nomor invoice. Untuk 
mendapatkan informasi tentang nomor invoice, konsumen dapat mengklik menu invoice yang ada dikelompokan keranjang belanja sebelah kanan website (Gambar 10).

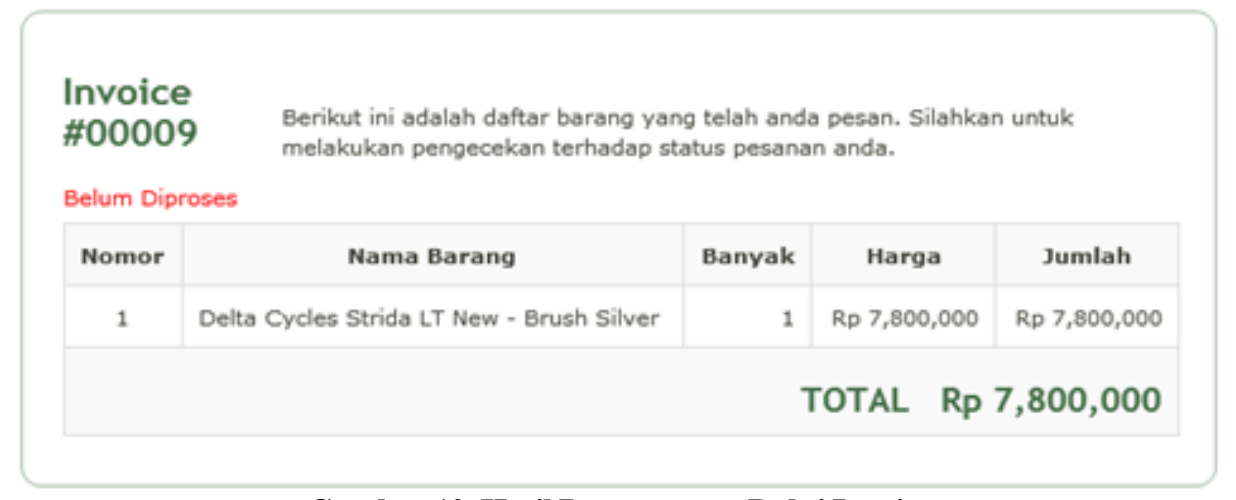

Gambar 10. Hasil Perancangan Bukti Invoice

Terakhir adalah fae pelaksanaan atau pengujian sistem.Pengujian ini dilakukan terhadap sistem informasi penjualan sepeda online yang berfokus kepada fitur dan fungsi sistem secara keseluruhan. Acceptance test ini berasal dari user stories yang telah diimplementasikan. Software testing adalah aktivitas-aktivitas yang bertujuan untuk mengevaluasi atribut-atribut atau kemampuan sebuah program atau sistem dan penentuan apakah sesuai dengan hasil yang diharapkan. Tahapan testing yang digunakan dalam penelitian ini adalah Unit/Component Testing. Unit testing merupakan proses testing, di mana melakukan proses testing pada bagian basic dari kode program. Memeriksa kode program pada event, procedure, dan function. Pada Unit Testing, memeriksa bagian kode program secara terpisah dari bagian yang lain dengan melakukan Unit Testing setiap kali sebuah kode unit (event, procedure, function) selesai dibuat. Validasi pengisian data member dimaksudkan untuk memastikan apakah data yang telah diisikan oleh konsumen tersimpan ke dalam basis data dan bisa langsung digunakan untuk masuk ke sistem dengan cara login. konsumen melakukan pembelian sepeda dengan cara memilih sepeda dan memasukkannya ke keranjang belanja. Berikut ini adalah kegiatan pembelian sepeda oleh konsumen (Gambar 11).

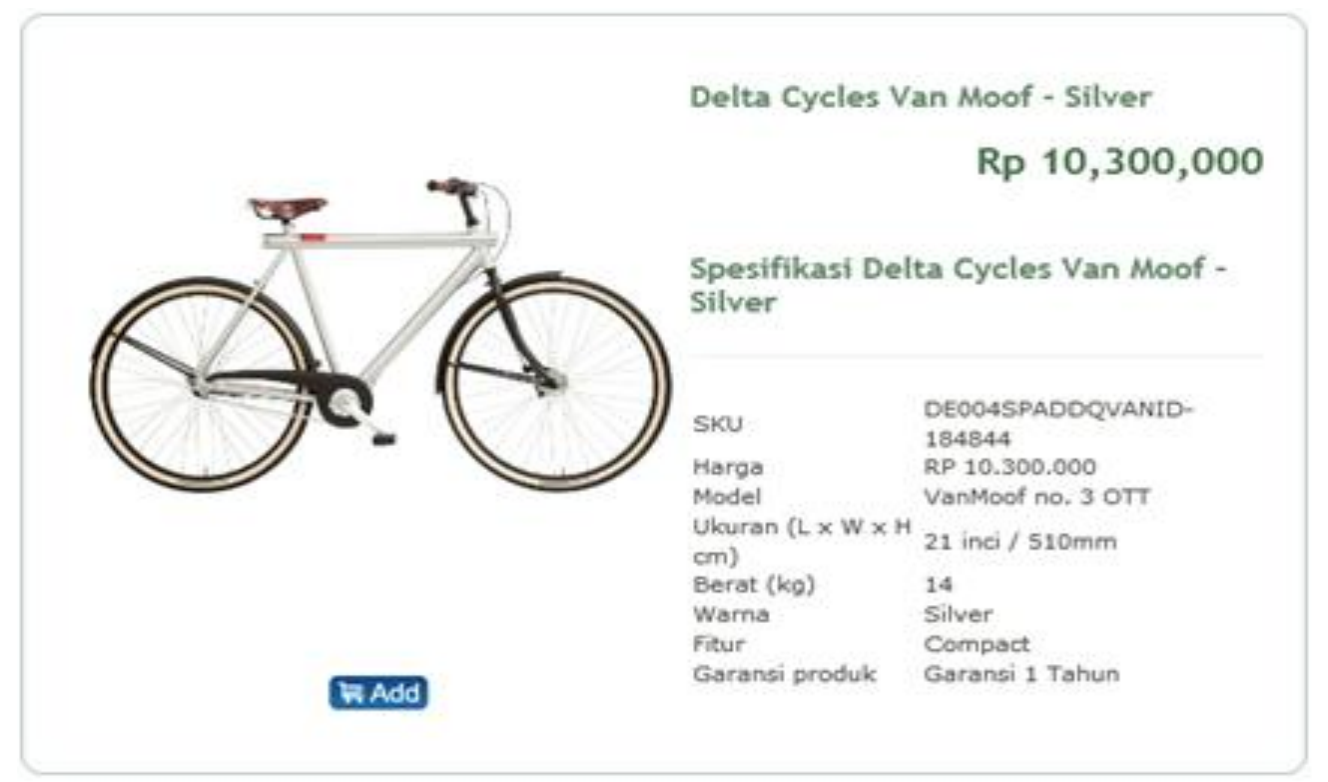

Gambar 11. Hasi Pengujian Informasi Pembelian Sepeda

Invoice ini adalah bukti transaksi yang telah dilakukan oleh konsumen namun belum diproses. Hal ini dikarenakan invoice tersebut belum diperiksa oleh admin. Apabila admin mengklik proses yang ada pada kolom Control, maka data tersebut sudah sah dan konsumen dapat melakukan proses pembayaran dan selanjutnya konsumen harus mengisikan data pada form konfirmasi pembayaran sebagai bukti kalau konsumen sudah mentrasfer uang (Gambar 12). Daftar invoice konsumen akan hilang setelah admin mengklik tombol proses. Berikut ini adalah tampilan yang membuktikan bahwa daftar invoice konsumen kosong (Gambar 13). 


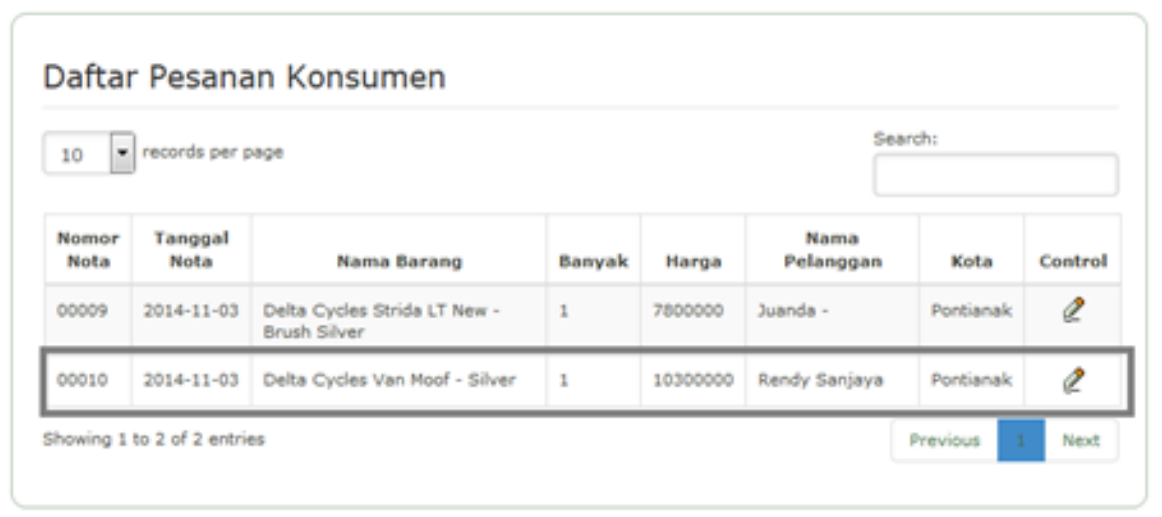

Gambar 12. Hasi Pengujian Invoice Belum Diproses

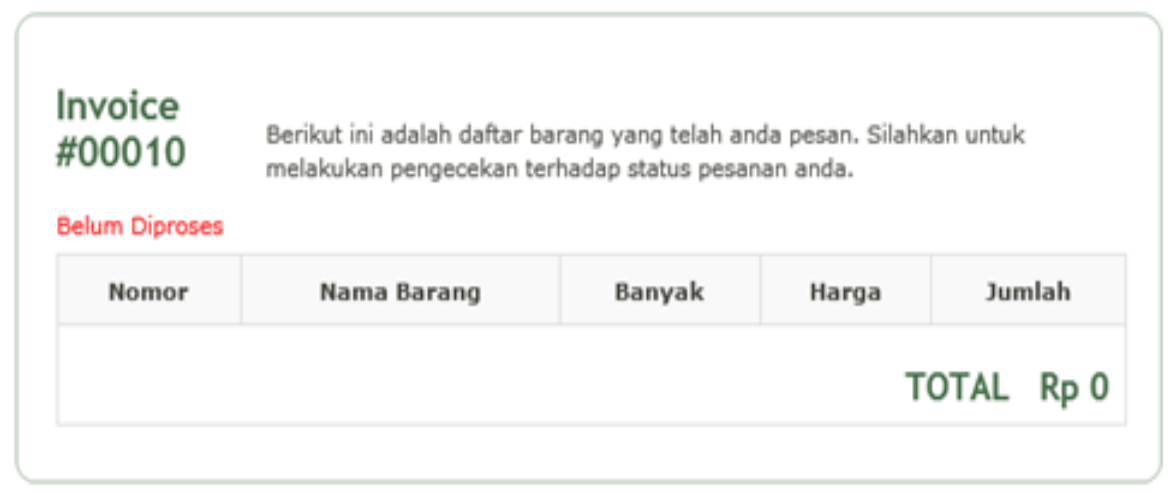

\section{Gambar 13. Hasi Pengujian Invoice Konsumen Kosong}

Selanjutnya melakukan verifikasi konfirmasi pembayaran. Konfirmasi ini bertujuan untuk memastikan apakah data yang diisikan oleh konsumen tersimpan dan bisa dilihat oleh admin. Setelah tombol submit diklik, maka data yang telah diinputkan seperti diatas akan tersimpan ke dalam basis data dan bisa dilihat oleh admin (Gambar 14).

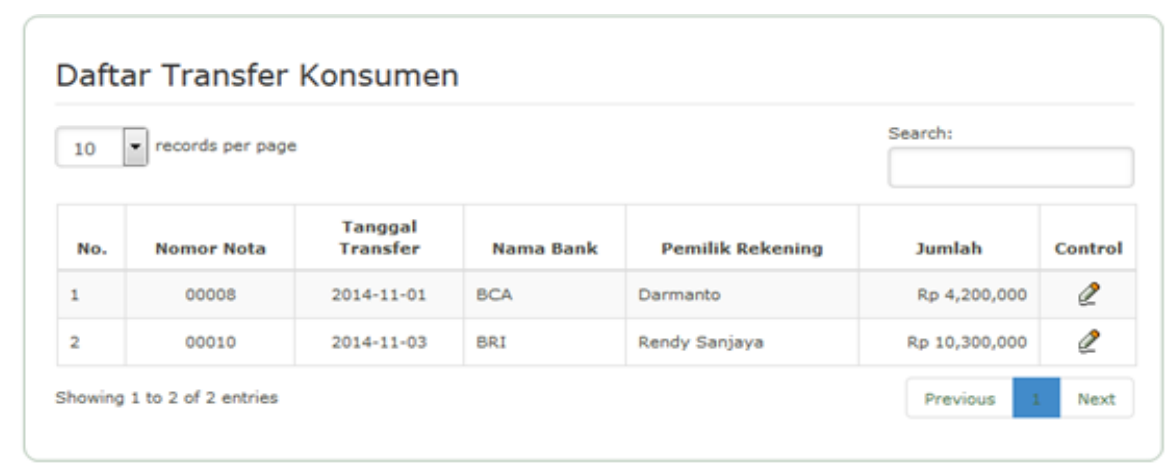

Gambar 14. Hasi Pengujian Penerimaan Transfer Pembayaran

\section{KESIMPULAN}

Melalui penerapan metode RAD (Rapid Application Development) dalam menghasilkan sistem penjualan sepeda online dapat memenuhi kebutuhan pengguna secara signifikan dan memberikan nilai tambah untuk pencapaian tujuan dan sasaran bagi UD. Polygon. Penyelesaian setiap modul perangkat lunak berdasarkan setiap tahapan dari metode RAD dapat berjalan dengan baik dan lancar. Sistem dapat memperkenalkan dan menjual produk sepeda kepada masyarakat luas. Hasil pengujian menampilkan sistem memiliki fitur navigasi dalam memberikan kemudahan bagi pengunjung, baik kepada konsumen ataupun pelanggan saat mengunjungi halaman webite UD. Polygon. Memiliki kontribusi menyelesaikan persoalan untuk memberikan jaminan layanan informasi yang lebih dekat kepada konsumen dan beralih ke proses digitisasi penjualan. Sistem sudah memiliki pesan-pesan tertentu dalam mengarahkan pengunjung, calon pembeli dapat melakukan proses pemesanan barang secara online kapanpun dan dimanapun serta mendapatkan informasi produk secara terkini. Kemampuan aplikasi digitisasi 
penjualan menawarkan banyak peluang baru terutama kesempatan memperluas jangkauan penjualan dengan biaya operasional yang lebih ekonomis.

\section{SARAN}

Untuk penelitian berikutnya, dapat menggunakan metode analisis dan perancangan lainnya yang merupakan bagian dari ADMMC (Agile based development methodology for mobile commerce applications). Untuk realisasi penerapannya membutuhkan kesiapan sumberdaya manusia dan ketersediaan infrastruktur teknologi informasi dalam kelancaran transaksi dan menjalin interaksi yang personal dengan konsumen (pelanggan) perusahaan. Hasil perancangan sistem penjualan sepeda online ini dapat dikembangkan dengan menggunakan perangkat mobile phone agar sistem dapat menjadi lebih fleksibel dan memudahkan dalam mengontrol setiap transaksi secara online. Untuk sisi client, semua produk dapat diakses melalui sebuah aplikasi yang berjalan pada berbagai platform perangkat mobile seperti Android, Symbian, IOS, dan lainnya.

\section{DAFTAR PUSTAKA}

[1] Britton, Carol., Doake, Jill., 2001. Object-Oriented Systems Development, ISBN 0-07-709544-8, McGrawHill, hal 28-29, 269.

[2] Pandey, Vishal., Bairwa, Avinash., Bhattacharya, Sweta., 2013. Application of the Pareto Principle in Rapid Application Development Model, International Journal of Engineering and Technology (IJET), Vol. 5, No. 3, Jun-Jul, ISSN : 0975-4024, hal 2649-2654.

[3] Muharom, Arzan., Cahyana, Rinda., Bunyamin., H., 2013. Pengembangan Aplikasi Sunda Berbasis Android Menggunakan Metode Rapid Application Development (RAD), Jurnal Algoritma, Vol. 10, No. 01, ISSN : 2302-7339, hal 1-11.

[4] Noertjahyana, Agustinus., 2002. Studi Analisis Rapid Application Development Sebagai Salah Satu Alternatif Metode Pengembangan Perangkat Lunak, Jurnal Informatika, Vol. 3, No. 2, Nopember, hal 74-79.

[5] Wahyuningrum, Tenia., Januarita, Dwi., 2014. Perancangan WEB e-Commerce dengan Metode Rapid Application Development (RAD) untuk Produk Unggulan Desa, Seminar Nasional Teknologi Informasi \& Komunikasi Terapan 2014 (SEMANTIK 2014), ISBN: 979-26-0276-3, 15 November, Semarang, hal 81-88.

[6] Aryanto, Arip., Tjendrowasono, Tri Irianto., Riasti, Berliana Kusuma., 2012. Pembangunan Sistem Penjualan Online Pada Toko Indah Jaya Furniture Surakarta, Indonesian Jurnal on Computer Science Speed (IJCSS) 13, FTI UNSA, Vol. 9, No. 3, Desember, ISSN : 1979-9330 (Print) - 2088-0154 (Online) - 2088-0162 (CDROM), hal 1-8.

[7] Hameed, A., Oudah, Ali., 2014. Improved Methodology for Mobile Commerce Applications, International Journal of Software Engineering and Its Applications, Vol. 8, No. 8, ISSN:1738-9984 IJSEIA, hal 29-42.

[8] Kendall, Kenneth E., Kendall, Julie E., 2013. Systems Analysis and Design, Ninth Edition, Prentice-Hall, Inc.

[9] Daud, N.M.N., Bakar, A.A.A., Rusli, H.M., 2010. Implementing Rapid Application Development (RAD) Methodology in Developing Practical Training Application System, Institute of Electrical and Electronics Engineers (IEEE), January 15, ISBN: 978-1-4244-6716-7, hal 1664-1667.

[10] Binsaleh, Muazzan., Hassan, Shahizan., 2011. Systems Development Methodology for Mobile Commerce Applications, International Journal of Mobile Computing and Multimedia Communications, 3(4), OctoberDecember, hal 36-52.

[11] Sommerville, I., 2010. Software Engineering, Ninth Edition, Addison-Wesley.

[12] Laudon, K. C., Traver, C. G., 2013. E-Commerce 2014: Business, Technology, Society, Tenth Edition, Prentice-Hall, Inc.

[13] Li, H., \& Hong, J. 2013. Factors Influencing Consumers' Online Repurchasing Behavior: A Review and Research Agenda. iBusiness, 5(4), 161-166.

[14] Kosasi, Sandy., 2014. Pembuatan Sistem Informasi Penjualan Berbasis Web Untuk Memperluas Pangsa Pasar, Seminar Nasional Teknologi Dan Informatika 2014 (SNATIF 2014), Edisi 1, Vol.1, 23 Agustus, Universitas Muria Kudus, ISBN: 978-602-1180-04-4, hal 225-232.

[15] Kosasi, Sandy., 2014. Pembuatan Sistem E-Commerce Produk Meubel Berbasis Komponen, 1st International Conference On Information Technology And Security 2014 (IC-ITechs 2014), 27 November, STIKI Malang, ISSN: 2356-4407, hal 66-74. 